ESCENA

Revista de las artes
Publicación semestral. ISSN 2215-4906

Volumen 79 - Número 2

Enero - Junio 2020

\title{
Panorama clown en Costa Rica
}

\author{
Clown Panorama in Costa Rica
}

Carolina Bertheau Carvajal

Carolina Zumbado Cambronero

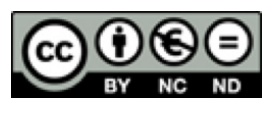

Esta obra está bajo una licencia Creative Commons

Reconocimiento-No comercial-Sin Obra Derivada 


\title{
Panorama clown en Costa Rica
}

\section{Clown Panorama in Costa Rica}

\author{
Carolina Bertheau Carvajal ${ }^{1}$ \\ Artista independiente \\ Costa Rica \\ Carolina Zumbado Cambronero² \\ Artista independiente \\ Costa Rica
}

Recibido: 16 de enero de 2019 Aprobado: 06 de marzo de 2019

\begin{abstract}
Resumen
El clown, en Costa Rica, como arte contemporáneo va en ascenso. Por lo tanto, hacer un escaneo de las percepciones de las personas involucradas en su forma artística se hace indispensable, para comprender su desarrollo en el país.
\end{abstract}

Palabras clave: clown; payaso; artistas; risa; formación; interdisciplinaridad

\begin{abstract}
The clown as a contemporary art is on the rise in Costa Rica, therefore studying the perceptions of the people involved in this art form is essential for understanding their presence in the country.

Keywords: clown; artists; laughter; training; interdisciplinarity

1 Artista independiente, cofundadora de Clowseria. Estudiante de la carrera de Arte Escénico de la Universidad Nacional de Costa Rica. Correo electrónico: carobertheau@gmail.com

2 Artista independiente, cofundadora de Clowseria. Licenciada en Artes Escénicas por la Universidad Nacional de Costa Rica. Correo electrónico: caro.zum2@gmail.com
\end{abstract}

ESCENA. Revista de las artes, 2020, Vol. 79, Núm. 2 (enero-junio), pp. 59-79 ISSN 2215-4906 


\section{Introdución}

Visibilizar, estudiar y sentar una base para el análisis del trabajo clown en Costa Rica es fundamental para su crecimiento. Al ser un movimiento contemporáneo, en desarrollo, el crear un mapeo de los hacedores y sus percepciones se vuelve indispensable para el análisis de las artes escénicas en el país. Una de las herramientas metodológicas para la obtención de información fueron las entrevistas semiestructuradas a distintas personas y agrupaciones relacionadas a la temática clown. En total se entrevistaron 48 personas, de forma individual o colectiva. Dentro del perfil de los y las entrevistadas se incluyen: practicantes del clown artísticos y sociales, especialistas e investigadores en clown, o temas afines en Costa Rica. Se busca sentar una base para el estudio del clown, pues al ser un movimiento cuyo desarrollo se ha dado en un lapso de quince años aproximadamente. Este trabajo se realizó gracias a la ayuda de PROARTES (Programa Nacional para el desarrollo de las Artes Escénicas) en el periodo 2017. Pero, quizás, el lector se preguntará qué es el clown. A continuación, una breve explicación antes de entrar de lleno a las percepciones de los artistas clown nacionales.

\section{¿Qué es clown?}

Durante el desarrollo de las sociedades ha existido una relación inherente del humano con la comicidad. Este ha sido tema de discusión tanto en la ciencia como en el arte, debido a su complejidad, naturalidad e importancia en la evolución humana. Existen muchas trayectorias para explorar la comedia y una de ellas es el clown. Se usará la palabra clown, inclusivamente, tanto para género femenino como masculino, pues no se distingue una diferenciación entre payasa, clown o payaso. La diferencia entre clown y payaso, deviene simplemente de su uso en español o inglés. De existir diferenciación sería con el payaso de entretenimiento/fiesta o el payaso de película de terror que no aplica en el estudio. Así, encontrar el origen del clown en el país o en el mundo sería una hazaña arqueológica, pues hay rastros de bufones, payasos y comediantes en todas las sociedades antiguas y contemporáneas, Costa Rica no es la excepción.

Definir clown no es una tarea fácil, ya que sus manifestaciones son muchas y muy variadas. Si bien el clown forma parte de la comedia y del humor, no se limita a esto, es un oficio que estudia la naturaleza intrínseca del juego, del ridículo y del absurdo humano. Por lo tanto, todos somos clown. Nos creemos todos bellos, inteligentes y fuertes, pero todos tenemos nuestras debilidades, nuestro ridículo, que al expresarse hace reír (Lecoq, 2007). Se puede estudiar el tema desde muchos ángulos. Por ejemplo, en el Diccionario de Teatro del autor Patrice Pavis (1984), desde el punto de vista antropológico, lo cómico responde al instinto de juego, al gusto por la broma y la risa, así como a la facultad de percibir aspectos insólitos o ridículos de la realidad física o social. Desde el punto de vista dramático, la 
acción se centra en los conflictos y peripecias que testimonian la inventiva y el optimismo del humano ante la adversidad. De hecho, la adversidad humana es el campo de estudio más rico para el clown. Este tiene el permiso social de jugar con la vulnerabilidad humana y, al hacerlo, libera la tensión del grupo.

Otro concepto importante se da a partir de la discusión si el clown es personaje o no, pues, este no existe fuera del intérprete. A diferencia del teatro o cine convencional en el que los actores representan personajes creados por otros. El caso, tal vez más conocido, para ejemplificar es Charlot el clown de Charles Chaplin. Si comparamos este trabajo con el de una actriz de cine -Julia Roberts, por ejemplo-, en cada una de sus películas Julia va a representar a un personaje distinto. Mientras que, en todas las películas de Chaplin, su vagabundo Charlot es el mismo. Un ejemplo más latinoamericano sería el Chavo del 8, por lo tanto, el clown es un ser único e irrepetible. La autora Louise Peacock añade que el clown tiene sus propias observaciones del mundo y de la vida. Así, busca comunicar al público y el juego se convierte en un medio para lograrlo (Peacock, 2009, p. 30). Lo cierto es que buscar una

Imagen 1. Clown Ivannia Alvarado y niño

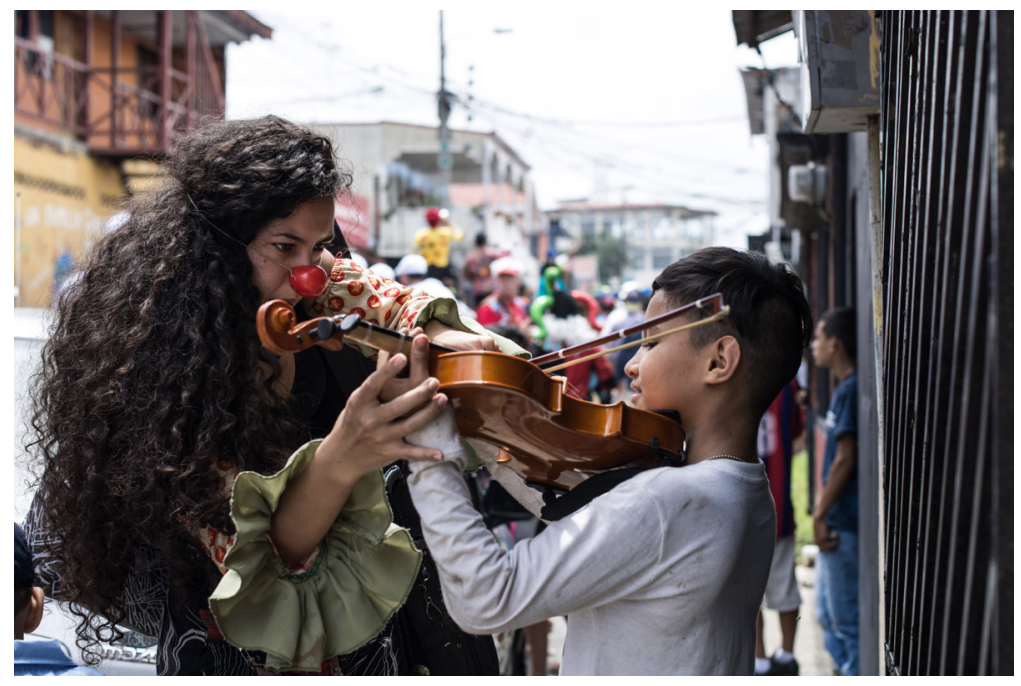

Fuente: Ivannia Alvarado, 2018.

definición para el quehacer del payaso, con frecuencia se encuentra en un terreno complicado de precisar. Esto debido a que intervienen varios factores en la percepción y en la técnica. "Un clown no es una abstracción ni una simplificación. El clown no es la simplificación de la tontería. Cada clown busca su manera particular y única de ser tonto y de hacer reír con ella" (Borras, 2003, p. 115).

\section{¿Qué es el clown para los artistas costarricenses?}

\section{El clown y su relación con el ser}

Cuando se le preguntó al artista nacional Emanuel "Tarrito" ¿qué es un payaso? confesó que, durante muchos años, le ofendió la pregunta: "es como si a uno le preguntarán, vos ¿qué 
tipo de humano sos? Soy del criterio de que yo soy el payaso. Porque es demasiado difícil dividir la cabeza en la parte civil y en la parte del payaso" (comunicación personal, 10 de marzo del 2017). La autora Louise Peacock, en Serious Play (2009), hace hincapié en la relevancia que tiene la retórica de uno mismo para todos los payasos, ya que la técnica del clown y su definición abarcan elementos fundamentales como el individualismo, la libertad, la metáfora y la subjetividad (Peacock, 2009, p.12).

Desde este punto de vista el clown es una expresión de una cultura propia. Decidir ser un clown es emprender un esfuerzo por comprender las bases genotípicas de su propia diversidad humana; aquello que le hace única o único y compartirlo con los otros. La dimensión de la poética individual, es un tema expuesto por muchos de los clowns costarricenses. A propósito, menciona la clown nacional Margarita Rincón:

Ser payasa es un arte que consiste en la exploración de uno mismo, de su propia medicina para el mundo, viene de la nobleza, de la humildad, del sentir, del vivir. El clown es la oportunidad que te da la vida de poder comunicar desde la manera más íntima de tu interpretación corporal, desde tu cuerpo, tu más sencillo sentir. (Comunicación personal)

Estas reflexiones plantean que las experiencias clown están, generalmente, integradas a la persona/creadora: en su memoria, sus emociones, conductas y, finalmente, en su autopercepción. La artista nacional Ruth Alvarado afirma que su personaje clown "Tuti" complementa a Ruth la persona, sus miedos, sus carencias. Asimismo, percibe al clown como una forma de ser y existir (Alvarado, comunicación personal, 11 de marzo del 2017). Si bien todos los artistas nacionales parecen coincidir con la idea de que todos somos clown. También consideran necesaria una trayectoria para encontrarlo, "para conectarse" con ese alter ego que van construyendo a lo largo de su búsqueda. Sergio Barrantes, fundador de Malabaristik se refiere al respecto;

Todos somos clowns, de cierta forma. Creo que es la persona que se conecta consigo misma y con los demás dentro de lo que es ese gran mar de la felicidad-de la risa-. Creo que lo principal es que uno mismo disfrute y se ría de sí mismo, creo que ahí es cuando sale el clown más natural. (Barrantes, comunicación personal, 24 de febrero del 2017).

No en vano, la búsqueda de su propio clown es un trayecto, en tanto que reírse de uno mismo no es tarea fácil, así como tampoco lo es crear poesía a partir de su propia individualidad. La sociedad tiende a defender valores genéricos y aplicarlos a todos por igual. Mientras que el clown valora y explora la diversidad genética de cada individuo. 


\section{La poética del clown}

A partir de su propia experiencia, el artista clown construye un ser alternativo que le permite explorar libertades que desconoce, vulnerabilidades que teme, amores que sufre. Posiblemente, es esta valentía la que, con frecuencia, lleva a conceder al clown una supremacía mística, mágica e incluso religiosa; se le otorga un universo mágico y poético. Mauren Salazar, artista escénica con experiencia en circo y clown expresa: "un clown es un ser mítico, que va jugando en varios espacios, en espacio físicos y espirituales. Puede ser animal y también humano. Puede ser claro y también oscuro. Es libre, está vivo" (comunicación personal, 23 de febrero del 2017). Para David Ramírez, de la agrupación Circo Canijo y Los Gangarilla, el clown es "poesía puesta en escena... el clown utiliza técnicas, fórmulas, y las trasciende y las abastece de poesía" (comunicación personal, 23 de febrero del 2017). Es la poesía puesta en escena uno de los retos más complejos de las artes escénicas. Un momento efímero que sucede en el escenario, tan volátil que recibe esta característica mágica y poética.

\section{La risa y otros humores}

Al consultar la opinión del Máster en Ciencias Cognitivas, Luis A. Piedra, sobre el humor y la risa, acota que son dos variables distintas, pero podrían estar juntas. Alguien que hace humor podría reírse, pero, existe humor que no despierta risa, sino otro tipo de situaciones. En cuanto se tiene buen humor se ríe, pero, se puede reír por angustia, tristeza y miedo. Los chimpancés, por ejemplo, cuando ríen están asustados, no lo hacen porque estén alegres. La risa es un mecanismo de carácter motor, vinculado a las emociones y que puede estar relacionada con el humor o no. Por lo tanto, el humor es un proceso y un estado, simultáneamente (comunicación personal, 6 de marzo del 2017). La risa es una de las características esenciales del clown, y no pasa desapercibida a la hora de dar una definición o plantear al payaso. Este elemento es considerado, por la mayoría de los artistas escénicos, como un medio para llegar a los corazones del público, para conectar con la audiencia y para encontrar su propio clown, David Azofeifa se refiere a la risa:

Generar la risa, claro, la risa consecuente, genera un montón de cosas, como la unión, la solidaridad: todo depende de cómo se maneje la risa. Este aspecto humano, esta herramienta transforma momentos, alimenta, entre todas sensaciones, emociones, que nos hacen bien. En otras palabras, ser payaso es como sanarnos (comunicación personal, 23 de febrero del 2017).

Para Kelcey Siobhan (comunicación personal, 10 de marzo del 2017) integrante de ASOCARTE (Asociación Cultura Arte y Circo), la risa y el humor son formas de romper barreras. Es un lenguaje universal que tiene particularidades culturales que conectan y podrían ser un aporte importante a la cultura latinoamericana. 


\section{La infancia y las emociones}

Otro rasgo importante que aparece, con frecuencia, en las definiciones de los artistas costarricenses es la asociación entre el clown y la infancia. Para Allan Castro, uno de los hermanos del Circo-Lo: "el clown es la magia de mantener al niño vivo" (comunicación personal, 21 de febrero del 2017). Asimismo, plantea una relación estrecha entre el clown-infante y el no tener reputación. El eliminar la reputación, el "qué dirán", le otorga libertad y le ofrece el permiso de jugar con las reglas sociales. Para la artista escénica Natalia Gutiérrez, la infancia se relaciona con el accionar clown en tanto que:

el clown es algo con lo que uno se encuentra a lo largo de toda la vida. Logra transportar a esos momentos o a esas emociones de infancia, de inocencia y de diversión pura. Para mí es eso, un viaje a esas emociones (comunicación personal, 19 de enero del 2017).

Ese viaje por las emociones conduce a una las definiciones más significativas en la teoría de clown, del libro titulado El clown, un navegante de las emociones desarrollada por el español Jesús Jara (2007). Este concepto fue mencionado, brevemente, en una de las conversaciones con el clown costarricense Marcos Seas (comunicación personal, 10 de marzo del 2017), mejor conocido como Tuto, quien afirma que al inicio de su carrera contemplaba al clown como un creador de emociones, sin embargo, luego de muchos años de trayectoria cree que el payaso aprovecha las emociones para crear. Muchas otras definiciones de los artistas clown costarricenses se enmarcan en la relación del clown y las emociones. A propósito, aporta Beto Garrapata: "un clown es la esencia del humano con rebote, todo lo básico, todos nuestros instintos, todos nuestros sentimientos" (Rodríguez, comunicación personal, 24 de febrero del 2017).

\section{Ser libre: una trayectoria clown}

Otro de los conceptos esenciales mencionado por los artistas costarricenses, en torno al desarrollo del clown fue la libertad. Si bien la libertad es un derecho que se nos es otorgado al nacer (entiéndase la libertad de seres humanos orgánicos, sin formas sociales incorporadas, sin la influencia del sistema educativo/familiar/contexto), estos factores van modificando el ser forjan el tipo de humano que se será. Entonces, cuando se habla de libertad clown se interconecta con el apartado anterior de la infancia. Es la libertad original del individuo la que busca el clown. A propósito, el artista Gabriel Romero enfatiza: "el payaso es un ser que vive en su máximo delirio de libertad” (comunicación personal, 22 de febrero, 2017).

Pero, alcanzar este libre albedrío tanto en el escenario como en la vida misma implica trabajo y requiere disciplina. Debido a que amerita capacidades físicas (libertad 
de movimiento) y estar presente (libertad emocional), habilidades artísticas (libertad para crear). Para el joven clown Iván Morales (comunicación personal, 10 de marzo del 2017) es una técnica virtuosa y no es a la ligera que funcionan las situaciones cómicas en la escena. Se precisa un estudio a profundidad y, a pesar de ser tan abstracto, se necesita formación intensa. Asimismo, los clowns son estudiosos y observadores de la sociología humana. A lo largo de la historia han ido descubriendo qué hace reír a la tropa de humanos, cuáles son las tensiones, tiempos y situaciones que deben generar. Los clowns entrenan como atletas; mil maneras de caer, de darse un golpe, de meterse en líos, de romperse el corazón. Se entrenan física y emocionalmente para fracasar. Es en esta línea delgada entre el virtuosismo y el error que el clown encuentra su poesía.

Para la agrupación Burumbum, el clown tiene una función social en tanto se vive en una sociedad donde lo más importante es el éxito. Mientras el clown es el personaje que representa todo lo contrario, lo cual logra que el público baje sus defensas y pueda ser libre, al aliviar la tensión social (comunicación personal, 6 de marzo del 2017). Por lo tanto, la libertad es otorgada no solo al artista sino, también, al público que observa el suceder escénico.

\section{El clown: un agitador social}

Si bien el clown es un personaje escénico es inseparable del ser humano. Desde este punto de vista, la cual le concede al payaso una función social, tal como lo definió el artista argentino, residente en Costa Rica, Sebastián Gaetano, un clown: "es un agitador social, un artista del pueblo" (comunicación personal, 25 de enero del 2017). El clown, desde sus inicios, se ha visto a la tarea de contradecir el sentido de bien público, desafiar los códigos establecidos y enfatizar en la apropiación de las individualidades. El enfoque de movilizar comunidades y espacios fortalece la idea de definir al payaso como un agitador social. Se convierte en un agente de análisis de contextos sociales, quien busca encontrar oportunidades que le permita crear acciones y repertorios que reten el contrato social establecido:

El clown es este personaje que hemos construido y que a lo largo de la historia ha pasado por un montón de cambios y en cada una de las culturas se puede ver un representante del clown, del inadaptado, del anormal, del que va a llegar a reírse con permiso, de hacer y decir las cosas como nadie más las dice, ese es el clown, el que tiene permiso de hacer lo que quiera, y lo vamos a perdonar porque nos lo está poniendo en el código perteneciente a la comedia, al humor (Cervantes, comunicación personal, 27 de febrero del 2017).

Para Jorge Calderón de la Compañía de Circo del Tercer Mundo el clown es un provocador, despierta conciencia y resalta que apoyándose en el humor se puede tocar temas complejos, pues "con humor las cosas entran mejor" (Romero \& Calderón, comunicación 
personal, 22 de febrero, 2017) Al conversar con la agrupación de clown social Burumbun, sobresale el elemento de influencia social, al definir al clown como un eje de cambio social y "como el arte de acercarse a la gente" (comunicación personal, 6 de marzo del 2017). Para Piedra (comunicación personal, 6 de marzo del 2017), el cometido del payaso en el grupo social es resaltar la función adaptativa de la especie humana. Siempre ha existido como figura y ha sido la persona encargada de alegrar la tropa (los grupos de humanos se denominan tropa), en momentos de mucha tensión. Las tropas humanas, en momentos de crisis, tenían a una persona que los entretuviese y para amenizar los conflictos que se presentaban.

\section{Payasa, payaso y clown}

Si bien se ha utilizado la palabra clown de forma general, muchos artistas costarricenses perciben una diferencia entre estos conceptos, el payaso nacional Pepe Picaporte acota:

La palabra clown no me gusta tanto, para mí, payaso y clown es lo mismo. Payaso es la traducción de clown ... El payaso es un personaje donde se pueden combinar todos los otros personajes, el arlequín, el bufón, el Augusto, el tramp ... Está el payaso de circo, de sala, de fiestas hay muchos estilos, pero todos son payasos. (Arias, comunicación personal, 27 de enero del 2017)

Estas distinciones de payaso planteados son esenciales para su estudio y subrayan la dificultad de su definición. Profundizar en cada una de estas categorías de payaso sería imposible, pues cada una de las categorías clown varían en género, origen, técnica e incluso estética. Pepe es el único de los entrevistados quien dice haber empezado como payaso y estar, actualmente, incursionado en su propio bufón. Sin embargo, no todos los artistas nacionales están de acuerdo. Mono hace una separación más marcada entre payaso y clown. Así, cree que deviene de una diferenciación técnica y que "cuando uno es clown, explora un montón de cosas, tiene que ser muy honesto, quien dice 'bueno ahora yo soy clown' es porque descubrió de verdad algo" (Solís, comunicación personal, 21 de febrero del 2017).

\section{Formación e influencias artísticas de los clowns en Costa Rica}

Existe un denominador común con respecto a la formación: no existe dentro del ámbito artístico costarricense un espacio dedicado plenamente al arte clown. Mientras que sí existen en el teatro, la danza e, indirectamente, al circo. A pesar de no existir este espacio es una necesidad creciente en el medio artístico nacional. 


\section{Aprendizaje empírico y en la calle}

Dentro de la formación clown en Costa Rica, el aprendizaje empírico y la búsqueda en el arte público tienen un gran peso. A esto se le atribuye una de las formas más frecuentes de aprender. "Creo que la formación más grande que hemos tenido ha sido la calle, el hecho de salir a la calle y exponernos y entregarnos, creo que ese ha sido el mayor aprendizaje" (Romero \& Calderón, comunicación personal, 22 de febrero, 2017). Históricamente, el clown representa un arte itinerante y popular. Tiene su mayor apogeo en el espacio callejero y Costa Rica no ha sido excepción. Si bien los espacios urbanos son cambiantes y van mutando con el tiempo los clowns se han adaptado para operarlos:

Empiezo a adentrarme en el mundo del arte callejero, a trabajar en los semáforos, comienzo a toparme con gente que hace arte callejero y muchos de ellos eran payasos Entonces, empiezo a conectarme con este otro círculo de personas que hacen un trabajo más de calle payaso y con ellos empezamos a hacer espectáculos (Azofeifa, comunicación personal, 23 de febrero del 2017).

El acercamiento con la calle genera el desarrollo de habilidades interpretativas, improvisación y volatilidad; artistas capaces y abiertos a lo que el público y sus compañeros de escena le ofrecen. Son pocas las disciplinas que permiten este contacto. El mirar al público es otro elemento que diferencia la técnica del clown con la técnica actoral tradicional. En el teatro, habitualmente, los actores representan la historia que les corresponde pretendiendo que los espectadores no los están viendo. Mientras que el clown sabe que los espectadores están presentes y va a interactuar con ellos. Esta ruptura de la cuarta pared podría tener su origen en este trabajo constante en el arte callejero.

En Costa Rica, al ser un arte desarrollado de manera empírica y tener pocos espacios de formación e intercambio, se encontró que muchos de los artistas clown utilizan el internet como medio de soporte para su investigación personal. Es una plataforma que les permite observar qué está pasando con el clown a nivel mundial y acceder, desde acá, al trabajo de artistas internacionales, por medio de entrevistas, material de apoyo, libros, videos, entre otros. La capacidad investigativa que amerita practicar clown reta, a quienes se interesan, a estudiar desde sus posibilidades. Muchos de ellos salen del país a capacitarse y son participantes activos de los festivales de teatro, circo y clown tanto a nivel nacional como internacional. Para el clown Charly Trapo: "hay mucha gente que se está capacitando, que está yendo afuera a capacitar. Además, en internet hay demasiado para ver, leer y aprender, hay muchas fuentes" (Aguilera, comunicación personal, 24 de febrero del 2017).

En los orígenes del clown en Costa Rica, cuando el uso del internet no era tan frecuente, formarse era aún más difícil. A propósito, comparte la payasa "Tuti" sobre su apren- 
dizaje a partir de la observación la estimulación de su imaginación con los materiales que podía conseguir (Alvarado, comunicación personal, 11 de marzo del 2017). Cuenta que, cada vez, que venía un circo era la oportunidad para ver y aprender del payaso.

\section{Interdisciplinaridad}

El clown como arte integral se nutre de otras áreas. Muchas de las personas que lo practican en Costa Rica derivan de otros lugares artísticos y buscan un enriquecimiento de su disciplina. Cada vez es más completa su práctica con personas de teatro, danza, artes visuales, ciencias sociales y salud. Por ser un arte poco conocido, la mayoría de las personas llegaron a él de una manera insospechada. En muchos casos iniciaron al practicar algún arte circense que les planteó el reto y la necesidad de incluir al clown como un medio para potenciar sus números y espectáculos. También, existen casos en los que su primer acercamiento fue un taller corto que les ofreció los primeros insumos del clown. En muchos de los casos, es descrito como amor a primera vista. La mayoría de las personas se identifican y sienten la necesidad de seguir experimentando el abanico de posibilidades que brinda el clown.

Por ejemplo, para Iván Morales (comunicación personal, 10 de marzo del 2017), integrante de ASOCARTE, el clown dentro del circo es indispensable y fundamental. Resalta el clown como herramienta para generar la empatía y el acercamiento con el público que otras disciplinas no ofrecen. Lo considera un puente entre lo que está sucediendo y el público, lo cual da como resultado una mezcla, una sola cúpula. Muchos de los artistas clown costarricenses cuentan cómo iniciaron con alguna disciplina artística para, luego, incorporar el clown dentro de sus números:

Te das cuenta que solo estás haciendo el número de malabares, que está muy bien, pero, llega un momento en el que se descubre que la risa y el clown generan algo más. Ese instante en el que ya se quiere convertir esta técnica en una acción teatral, en algo cómico (Castro, Castro, Castro \& Castro, comunicación personal, 21 de febrero del 2017).

Kelcey Siobhan, integrante de ASOCARTE y coautora del libro El circo en Costa Rica, señala que durante su investigación se percató que en Costa Rica: "existe mucho clown y, de hecho, en la investigación encontramos que la gran mayoría de personas que participan como artistas o practicantes del arte circense tienen un personaje clown" (comunicación personal, 10 de marzo del 2017).

ESCENA. Revista de las artes, 2020, Vol. 79, Núm. 2 (enero-junio), pp. 59-79 


\section{El clown dentro de las academias}

El arte clown, como hecho escénico enriquecedor, está completamente relegado dentro de los espacios formales artísticos del país. La mayoría de practicantes del este arte y quienes, además, tienen formación en las academias artísticas (Universidad Nacional de Costa Rica y Universidad de Costa Rica), resaltan la importancia de incluirlo, activamente, dentro del plan de estudios. Para, así, dejar de contemplarlo como un hecho aislado que no concierne a la formación de las artes escénicas nacionales.

Al respecto, comenta una integrante de la agrupación Tres Hermanas, egresada de Artes Dramáticas de la UCR: "yo creo que debería incluirse clown, precisamente, para ver

Imagen 2. Espectáculo la vida seria de las personas Las Tres hermanas

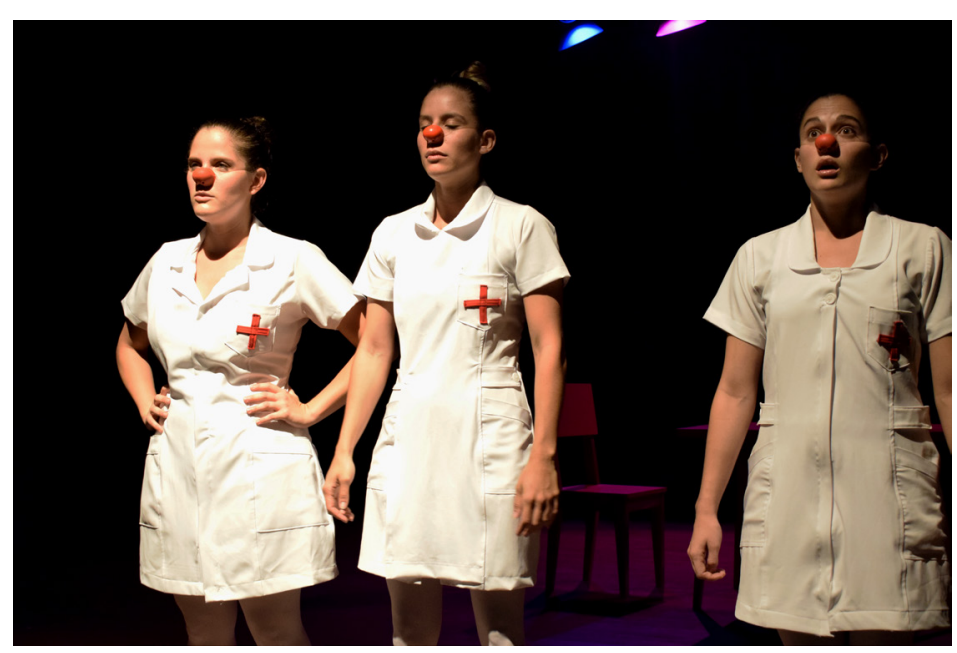

Fuente: Pablo Molina 2017. si tenemos la oportunidad de desestructurarnos, de dejar de pensar de una forma tan lineal y empezar a encontrarse más con uno mismo, tan necesario para poder ser creadores" (Jiménez, comunicación personal, 19 de enero del 2017). Dentro de las academias formales costarricenses existe un modelo marcado de enseñanza actoral, que provoca un lenguaje en común entre los actores y las actrices. Pero, también puede ser una limitante que estructura al sujeto en un tipo de actuación. Por esto, se contempla al clown como una oportunidad para "desestructurarnos". Brenda Barrantes, integrante de la agrupación Colectiva Respiral y artista especializada en teatro aplicado, acota con respecto a la poca presencia del clown en espacios formales:

Pues debería y sí se necesitaría que exista más ese diálogo. Pero, el clown sigue ahí, es como el hobby, así que "vaya investigue usted por su lado. Aquí, en esta cosa cuadrada formal académica no me meta esas cosas que no funcionan". Mientras que, al revés daría muchísimas más herramientas, expresivas, comunicativas, de revisión, del trabajo desde la vulnerabilidad, las cuales, yo creo que hacen mucha falta (Barrantes, comunicación personal, 10 de marzo del 2017). 
El clown, por lo tanto, genera un espacio de intercambio y diálogo entre lo formal y lo no formal, entre la calle y la academia, entre distintas disciplinas artísticas. Este es propiciado por los intérpretes e interesados en el tema. Son ellos quienes creen que el clown en Costa Rica se vuelve una necesidad que debe ser escuchada por los espacios académicos y formales.

\section{Espacios posibles de formación clown en Costa Rica}

Debido a la poca inclusión del clown dentro de las academias formales artísticas, existen espacios alternativos que, en ocasiones, brindan la posibilidad de talleres cortos de formación. Por ejemplo, la Escuela de danza, teatro y circo-Parque de la Libertad, continuamente, abre talleres de formación enfocados en las artes circenses. Este paraguas de disciplinas variadas incluye al clown. Se dan talleres con maestros internacionales y agrupaciones, por lo tanto, resultan de gran valor para la formación en el país. Estos talleres tienen una duración aproximada de dos a tres semanas, de carácter intensivo, y quienes participan, tienen la oportunidad de explorar distintas técnicas planteadas por los facilitadores. Aun así, no se ofrece una profundización y continuidad al proceso, para funcionar como un espacio de formación permanente. Asimismo, no estudia, exclusivamente, al clown si no a todas las disciplinas relacionadas al circo.

Otro de los espacios de formación sobresalientes son los generados desde ASOCARTE, los cuales, también, se dan en tiempos cortos, pero intensivos. Además, como conjunto propician conversatorios, espacios de diálogo y discusión, así como festivales y encuentros internacionales. "La Asociación debería y va a seguir en estos proyectos más amplios, accesibles a bastantes personas que siempre van a incluir formación en clown" (Siobhan, comunicación personal, 10 de marzo del 2017). ASOCARTE abarca todas las manifestaciones circenses en el país. Incluye dentro de sus proyectos al clown, como una gran sombrilla que busca permear al circo y crear espacios de formación, según las necesidades de sus asociados.

También existió una escuela de payasos que, a pesar de su enfoque comercial y de payaso de fiesta, fue fundamental como primer acercamiento, para la formación de algunos clowns en Costa Rica. Paraguas rojo funciona, aproximadamente, desde el año 1990 y fue un punto importante de formación para clowns como Pepe Picaporte, Iván Biolley, Elena Picado, Sebastián Ramírez, entre otros. A pesar de la influencia y enfoque de payaso de fiesta, Paraguas Rojo permitió que estos artistas dieran el siguiente paso al clown más escénico, les abrieron puertas y marcaron el inicio de un trabajo de vida:

Nos conocimos en una escuela de payasos hace 11 años ... cuando salimos de la escuela nos quitaron el trajecito, la nariz y fue cuando vimos que no teníamos el 
Imagen 3. Joven clown Dabit Azofeifa

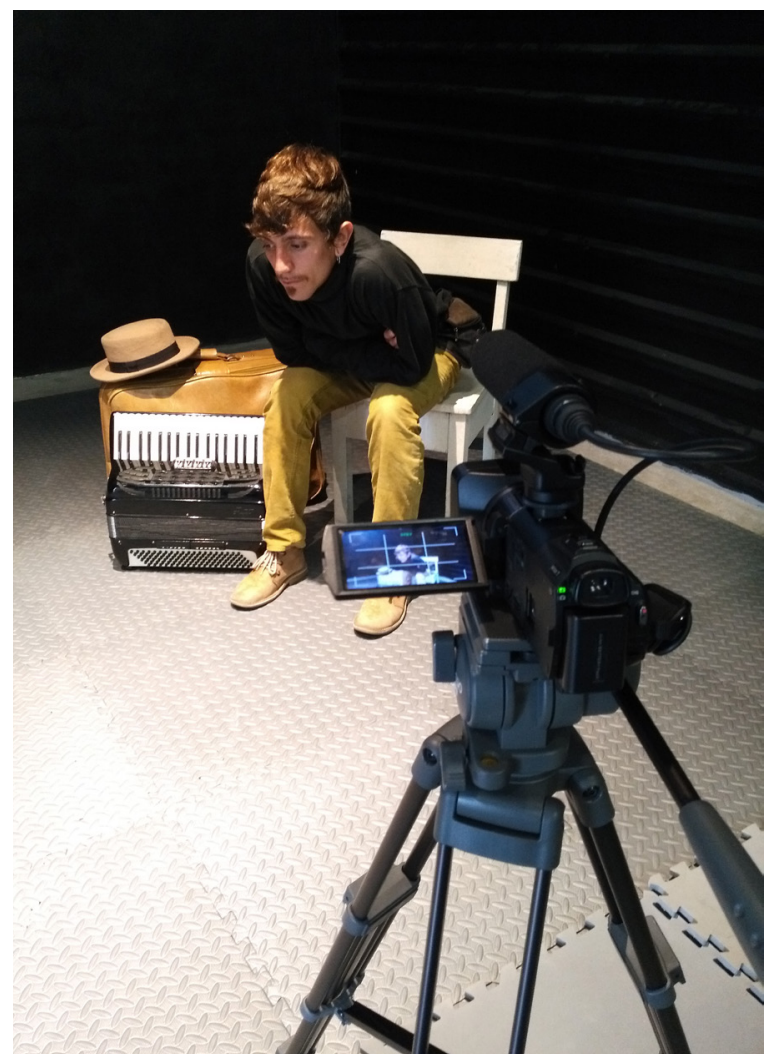

Fuente: Clownseria 2017.

dominio, ni el conocimiento de la técnica. No teníamos las cosas ordenadas de forma que pudiéramos crear algo con la experiencia y el conocimiento que nos dieron. Ahí fue cuando comenzamos una investigación un poco más profunda (Biolley \& Picado, comunicación personal, 6 de marzo del 2017).

Además, existen iniciativas de gestión independiente que sustentan esta necesidad de formación y, en ocasiones, promueven espacios alternativos clown en el país. Lamentablemente, estos no llegan a más, dada la situación del país y contexto que se vive. Los anteriores son algunos de los espacios de formación que, a pesar de existir y de estar disponibles en el medio nacional, no cumplen con los requisitos necesarios para promover un espacio de estudio formal y de profundización en el arte clown.

\section{Acercamiento internacional}

Una gran cantidad de las personas entrevistadas, practicantes del arte clown, en Costa Rica, también han tenido un acercamiento más profundo desde la perspectiva internacional. Gracias a algún viaje en el que llevaron talleres, al establecer contactos de intercambio, al participar en festivales que reunían gran cantidad de clowns, bufones o artistas cómicos. También, debido a la presencia de facilitadores extranjeros en el país. Para Pepe Picaporte, la experiencia a nivel internacional ha sido muy importante en su formación:

Prácticamente, ha sido lo que he venido a aprender de bufón, de esta técnica, sobre todo en este encuentro de bufón, porque es un acercamiento. Todavía estoy en el proceso de creación de este personaje (Arias, comunicación personal, 27 de enero del 2017).

Desde los inicios de la práctica, en Costa Rica, como en el clown contemporáneo, la visita de los circos internacionales ha sido de gran importancia. Para el artista Ernesto Elizondo una de sus mayores influencias se dio gracias a la venida de los circos extranjeros.

ESCENA. Revista de las artes, 2020, Vol. 79, Núm. 2 (enero-junio), pp. 59-79 
En estos podía ver a los payasos en acción, lo que, posteriormente, concretó con su participación en un taller con un artista internacional en suelo nacional (comunicación personal, 10 de marzo del 2017). Cabe mencionar que Costa Rica es vista como un puente de intercambio artístico, tanto por los artistas nacionales como internacionales. Esto propicia un compartir que influye en la formación clown del país. En general, se puede considerar que la influencia internacional está presente en la exploración del arte clown y que la mayoría de los practicantes se ven seducidos por este factor, debido a la ausencia de espacios de formación en el medio costarricense.

\section{Influencias de clown en Costa Rica}

Dentro de la información recopilada, existen artistas clowns residentes en Costa Rica, los cuales resultan influyentes para las agrupaciones o clowns que, actualmente, se desempeñan en el medio nacional. Debido a su presencia en la activación del espacio urbano o la calidad e innovación de su trabajo. A continuación, se hará referencia a las agrupaciones más influyentes mencionadas por los y las artistas. Una de las más evocadas fue La Compañía de las 3B, agrupación formada por el argentino Jorge Alberto Solís (Mono) y el costarricense Carlos Aguilera (Charly Trapo). También el clown argentino Sebastián Gaetano (Araknido), el bufón tico Joan Arias (Pepe Picaporte) y la agrupación Los Malafachas, conformada por la costarricense Laura Cordero (Lola carambola) y el guatemalteco Carlos Leiva (Karim). Vale la pena resaltar que fueron muchas las personas influyentes que se mencionaron en el proceso. Pero, estas agrupaciones o artistas son las que se mantienen como denominador común, sobre todo por las nuevas generaciones, que se encuentran practicando el arte clown:

Como, por ejemplo, Jorge Solís, Mono, que aún se mantiene firme y que ha sido uno de los que vivieron este proceso del nuevo circo en Costa Rica y que aún se mantienen y así antes de él hubo otros. Pero, bueno la generación que a uno le toco le llegó la información de estos de forma directa (Castro, Castro, Castro \& Castro, comunicación personal, 21 de febrero del 2017).

Fue hace más de 20 años que Jorge Solís (Mono) llegó a Costa Rica con su propuesta de clown gestual. En ese momento había un mayor apogeo de formación e influencia de payaso de fiesta, el cual él no exploró. Se unió al clown costarricense David Ho, para profundizar más en este arte. Con respecto a las posibilidades de formación, Jorge Solís señala que:

En ese momento había mucha gente "mochileando" o viajando, ahí comenzamos a encontrarnos. Costa Rica es para nosotros como un lugar de paso, iniciamos el semáforo, como que todos eran aspectos para explorar, mostrarse. Entonces ahí 
se fueron dando un montón de encuentros, de ganas, de "uy que bueno esto" (Solís, comunicación personal, 21 de febrero del 2017).

Posteriormente, también llega al país el argentino Sebastián Gaetano (Araknido). Él es parte de los clowns que han influenciado el apogeo e interés en las nuevas generaciones por este tipo de arte más escénico y artístico en contraposición con el payaso de fiesta, el cual se encuentra más consolidado en el país.

Hay cierta gente que ha venido también. Costa Rica es un lugar de paso, aquí han pasado muchos locos clowns, malabaristas, acróbatas y muchas influencias de afuera. Creo que nos ha marcado muchísimo y ha determinado que haya un auge fuerte en el clown (Barrantes, comunicación personal, 24 de febrero del 2017).

Imagen 4. Compañía de las 3B Jorge Alberto Solís (Mono) y Carlos Aguilera (Charly Trapo)

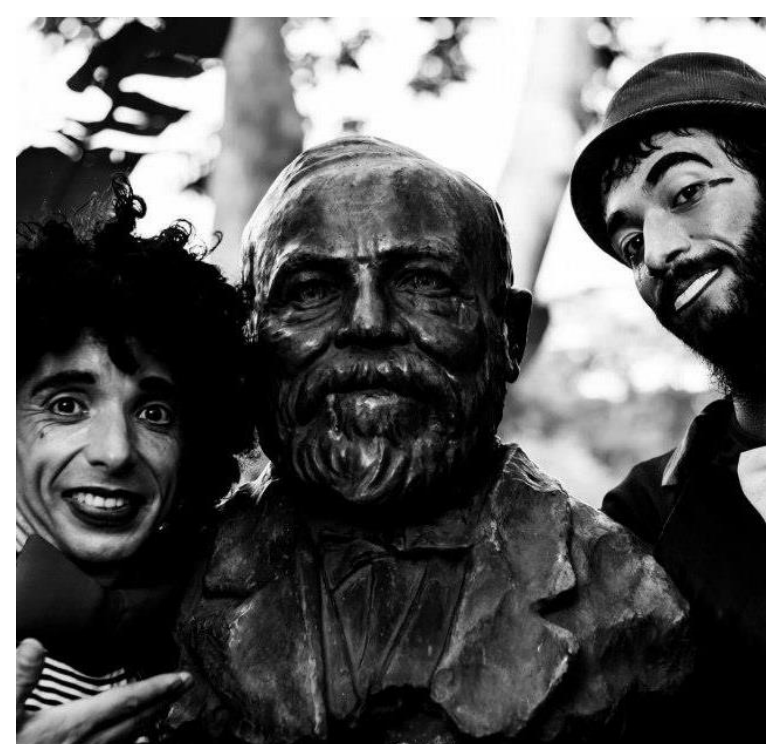

Fuente: Carlos Aguilera 2011.
De igual forma, se menciona al bufón/ clown Pepe Picaporte, como uno de los artistas costarricenses con más presencia internacional en talleres, festivales y con conexiones al exterior. Cabe destacar que Pepe se ha presentado en importantes escenarios de América Latina. Esta cualidad, del círculo artístico costarricense que es descrito como: "un lugar de paso" permite que el clown desarrolle aún más sus cualidades itinerantes de calle. Esto facilita el contacto con otros artistas, tanto nacionales como internacionales (destacan los suramericanos y centroamericanos). Gracias a esta cualidad, el clown, en Costa Rica, se ha visto marcado e influenciado por personas que vienen desde el extranjero, quienes han propiciado un mayor auge y desarrollo de este arte. Así, han marcado los procesos de formación de los clowns costarricenses.

\section{Retos del clown costarricense}

Los retos surgen a partir de la óptica de distintos intérpretes y practicantes del clown. Por lo tanto, se realizará una recopilación de los mencionados con más frecuencia o de puntos compartidos. Es importante recalcar que, el payaso existe, en Costa Rica, desde hace muchos años. Se ha consolidado como payaso de entretenimiento, animación o fiesta. Por lo tanto, la propuesta de clown más escénico es un arte contemporáneo, que ha crecido 
con la ola del nuevo circo. Es una propuesta novedosa que borra las líneas entre el circo, el clown y las artes escénicas. Esto permite la incorporación de artistas más integrales y capaces. Pero, esta libertad puede ser una oportunidad o puede representar un espacio vacío, debido a las ineficiencias de formación y los pocos espacios con los que cuenta el medio clown costarricense.

Por ejemplo, el mayor reto tiene que ver con los espacios de formación inexistentes en el ámbito artístico costarricense. Se menciona que, no existe un espacio de formación dedicado plenamente al arte clown. Se conocen espacios alternativos y de poca duración, que abren, momentáneamente, las puertas a esta disciplina. Sin embargo, no hay un espacio que se dedique plenamente a la profundización, estudio y dedicación de este arte. Además, tampoco existen espacios de intercambio, que permitan la convivencia de las personas interesadas en festivales, conversatorios, simposios o congresos, que reúna a los practicantes o investigadores del clown tanto a nivel nacional como internacional. Esta falta de espacios de convivencia provoca que, la mayoría de los clowns del país trabajen para entidades privadas y para un tipo de público en específico. Existe, por lo tanto, muy poco apoyo por parte del gobierno, lo cual provoca que los artistas clowns tengan que apostar a la empresa privada, para sostener sus espectáculos y vivir de su arte.

Para Sebastián Gaetano, con más de quince años en la escena nacional: "se necesitan más espacios, más apoyos gubernamentales, más protección gubernamental quisiera decir, para que se pueda desarrollar más. Ahora estamos expuestos solo a la decisión de una empresa o un productor, entonces, necesitamos libertades" (Gaetano, comunicación personal, 25 de enero del 2017). Pues, el apoyo brindado por las instituciones públicas o los medios estatales son insuficientes, casi inexistentes y acaparados por personas o entidades excluyentes.

Por tanto, uno de los retos de los artistas clown costarricenses se encuentra enmarcado por las oportunidades que faciliten la creación de material escénico, el cual se ve eclipsado por la falta de apoyos, espacios y capital. Este último, en manos de empresa privada, que ha aportado al desarrollo del arte, pero, también, han limitado su alcance. Iván Biolley (Biolley \& Picado, comunicación personal, 6 de marzo del 2017) apoya la idea de Araknido y señala que, la salida comercial del clown se ha quedado en manos de empresas privadas que solo brindan el capital, lo cual ha limitado la parte creativa, artística y lo que se quiere comunicar.

Desde luego, para la empresa privada, que busca satisfacer las necesidades del mercado exigente, representante del sistema capital dominante, el clown como agente de cambio, de auto búsqueda y metáfora escénica no calza dentro de sus formatos de interés. Aun así, es vista como un medio de subsistencia, que permite a los artistas satisfacer sus 
Imagen 5. Pepe Picaporte en el Festival Guatecirco 2018

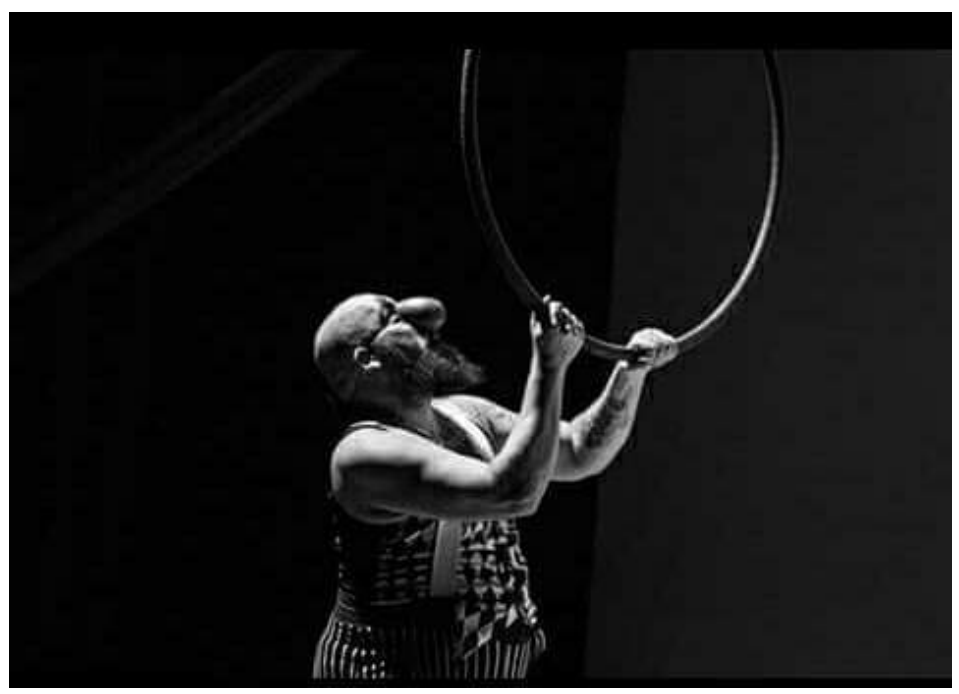

Fuente: Carlos Bernardo Euler Coy necesidades económicas y brinda cierta estabilidad. La falta de espacios de formación e intercambio, también provoca que el arte clown no se perciba de manera seria y profesional. Son muchas las personas que se hacen llamar clown, sin llevar un proceso de preparación, profundización, ni estudio serio. Esto facilita que se practique de una manera poco profesional, lucrativa e interesada, lo cual afecta, directamente, al medio y confunde al público, sobre la percepción de qué es el clown. De esta forma, existe una necesidad inherente, que representa un reto para el panorama clown costarricense: promover los espacios de formación e intercambio serios y reales:

Van a existir más clowns, pero, van a existir más clowns buenos si realmente estos hacen una búsqueda honesta sobre la técnica. No conformarse con lo que vemos en una computadora, o lo que vemos en teatro, sino, realmente, tiene que haber una necesidad de información para que la técnica suba (Morales, comunicación personal, 10 de marzo del 2017).

Esto acontece debido a la desorganización del gremio, que no genera enlaces ni busca agrupar a sus miembros en una organización que le represente, con el objetivo de pautar los lineamientos para hacerse llamar clown. La organización más cercana es ASOCARTE, la cual abarca todas las manifestaciones del circo y, por lo tanto, no se puede especializar en el clown. Algunos describen al ambiente clown costarricense como ameno y fraternal. Pero, se mencionó que es pequeño y cerrado, con mayor apogeo en la Gran Área Metropolitana. También, se comentó sobre la falta de unión, ya que pareciera estar un poco dividido, sus integrantes trabajan de manera aislada y sin generar enlaces entre sí:

Necesitamos apoyarnos entre todos, necesitamos acabar con el pensamiento de que somos diferentes o que venimos de otro lado, sino, trabajar todos juntos, porque el circo siempre ha sido una institución internacional. El circo siempre ha alojado 
a los diferentes, a los raros y, entre esas diferencias, también hay que aceptar que existen formas y expresiones variadas, no solo hay una, sino, que hay miles, que van a haber más y, entonces, apoyar esas miles (Gaetano, comunicación personal, 25 de enero del 2017).

Otro reto importante por afrontar es la consolidación de un clown tico, que pareciera estar en proceso. Al enfrentarse a un medio pequeño, que busca innovación y nuevas ideas para sus propuestas, a la hora de abordar el hecho creativo. Se seguirá gestando, de manera paulatina, al evolucionar hacia ese camino, hacia la búsqueda de formas propias de creación, de un estilo de clown que pueda representar y dar fe del trabajo de los y las ticas:

Últimamente, en los últimos días, he visto como que ya los espectáculos de clown que tenían un contenido de habilidad circense muy grande, han ido cambiando, ya han salido "compas" que han expuesto otros trabajos, más en el crear cuestiones meramente escénicas (Elizondo, comunicación personal, 10 de marzo del 2017).

A la consolidación de un clown tico, también, se debe agregar la consolidación de un público, que se familiarice con el concepto del clown, el cual se acostumbre a este arte más escénico, menos dirigido a la animación y a la fiesta. Pues, a pesar de que ambos poseen un factor de divertimento y risa, sus fines y formas son distintas. Estos son algunos de los retos a los que el panorama del clown costarricense debe hacer frente. Son retos que ponen en evidencia carencias existentes, para lograr superarlas es necesario la unión del medio y "un marcaje más claro de la cancha en la que se está jugando". Al ser el clown un arte tan novedoso en el país, no deja de representar un espacio en construcción que, a la larga, puede dar muchas posibilidades de crecimiento, no solo en el medio interno del ejercicio, sino a nivel interdisciplinario, al nutrir otras prácticas y, por qué no, a nivel internacional, al marcar una pauta de cómo hacer clown.

\section{Conclusiones}

El panorama clown, en Costa Rica, se encuentra en crecimiento constante, junto con la oleada del nuevo circo, el cual se desarrolla hace, aproximadamente, veinte años a nivel mundial. El nuevo circo incluye nuevas formas enfocadas en los intérpretes, deja de lado el uso de animales en sus números y desarrolla métodos más escénicos, con la inclusión de herramientas teatrales, de danza, musicales y artes visuales. Existe, por lo tanto, un crecimiento en el panorama clown costarricense. Pero, de manera desorganizada y en desmedida, que puede ser una ventaja y, a la larga, también un factor en contra de quienes pretenden tomarse este arte con seriedad y profesionalismo. 
Se observa una carencia de espacios y fondos culturales que permitan favorecer el fortalecimiento y desarrollo de la base práctica y teórica del clown. Los esfuerzos más consolidados son realizados por el sector independiente, con los Encuentros Nacionales de Circo, producidos por ASOCARTE, como una de las actividades principales para el crecimiento del sector. Así, en Costa Rica, existe una nueva forma de hacer clown contemporáneo, que discierne del payaso de animación y va en ascenso. Pareciera que los agentes que se conjugan para que este arte salga a flote deberían estar más organizados, tanto a nivel estatal como gremial.

Imagen 6. Clown Gabriel Romero

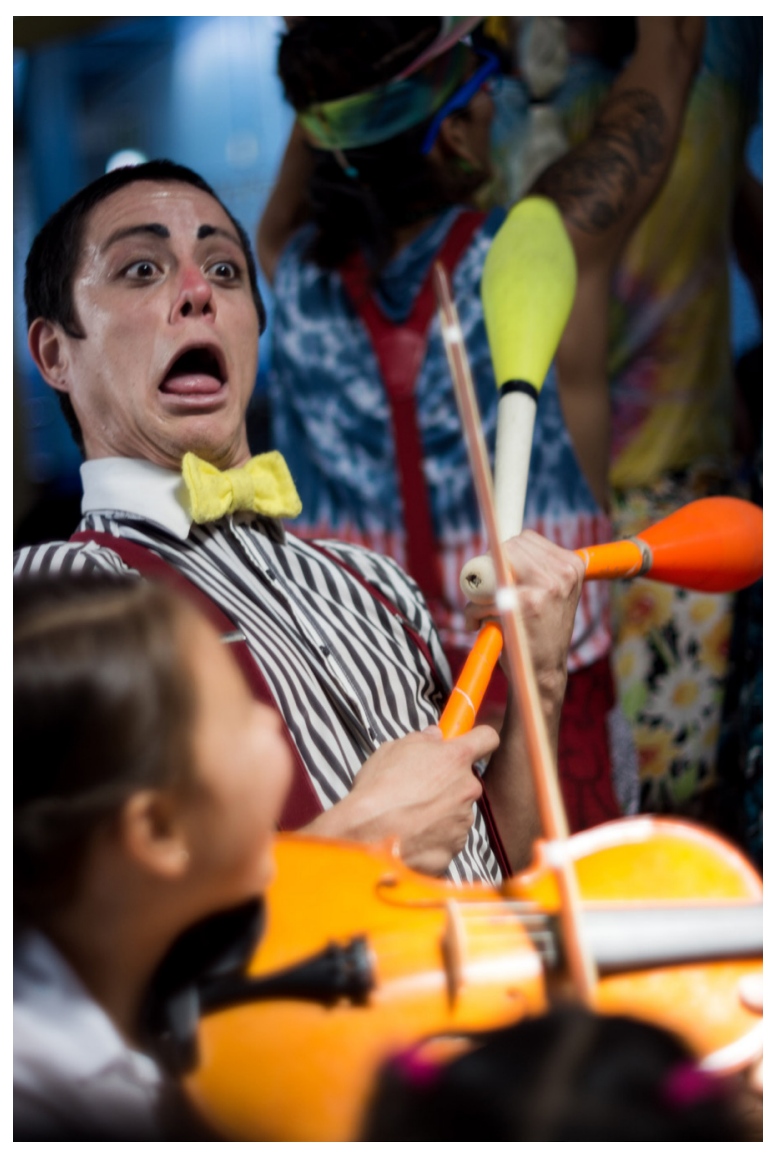

Fuente: Ivannia Alvarado fotografía 2018.
La consolidación del clown tico puede verse eclipsada por la estandarización y dominación de la cultura anglosajona y europea, al no existir espacios que favorezcan la producción de conocimiento y experimentación, desde de la cultura local. De este modo, resulta importante que los payasos y el público sean conscientes de su papel activo en la construcción de movimientos sociales y de las características de las situaciones clown: género, audiencia y el cómo se construyen historias, desde la naturaleza propia de este arte. Asimismo, se considera importante la publicación académica, la divulgación del pensamiento crítico y habilidades del mundo clown, con el fin de enriquecerlo. Al mismo tiempo, esto permite diversificar al público, al fomentar su participación y ampliar la percepción del mundo del payaso. La producción intelectual artística, en Costa Rica, también está en crecimiento. Poner en discusión un tema nuevo, como lo es el clown, abre un espacio para reflexionar sobre las formas de hacer arte y las condiciones a las que los artistas se tienen que enfrentar. Se podría considerar que, hacer clown en un país con tantas limitantes culturales es casi un lujo y representa todo un reto para quienes incursionan en este camino. 
La captación de fondos artísticos, para el desarrollo de proyectos relacionados con la temática clown es una limitante. Pues, a nivel nacional los fondos culturales con los que se cuentan son pocos para la alta demanda y la variedad de propuestas artísticas. Estos fondos tienen que rendir para un gremio independiente, que va en ascenso y representa al país. El desafío está en desarrollar nuevas formas de integrar a los distintos agentes que, tradicionalmente, han sido generadoras de la producción y autenticación del conocimiento artístico. Este sería un vehículo importante para el desarrollo del clown como una técnica legitima, distinta a las artes escénicas y circenses. Se busca dejar en evidencia qué está sucediendo en el medio clown y artístico nacional. Así como evidenciar quiénes son hacedores, qué está sucediendo y donde hay que poner énfasis, para un surgimiento seguro y fuerte del arte clown.

\section{Referencias}

Borras, M. (2003). El clown: ¿personaje? o ¿no-personaje? [Presentación]. Aula mayor de la Universidad Pedagógica Bogotá, Colombia. Narices rojas (pp.112-121).

Jara, J. (2007). El clown, un navegante de las emociones. Sevilla: Proexdra.

Lecoq, J. (2007). El cuerpo poético, una pedagogía de la creación teatral. Barcelona: Alba Editorial S. L. U.

Pavis, P. (1984). Diccionario de Teatro: dramaturgia, estética, semiología. Barcelona: Ediciones Paidós Ibérica.

Peacock, L. (2009). Serious Play: Modern Clown Performance. Chicago, USA: Intellect Bristol, UK.

Swortzell, L. (1978). Here Come the Clowns: A Cavalcade of Comedy from Antiquity to the Present. New York: Viking Press. 